\title{
Nonlinear Dynamic Response of RC Buildings with Different Base Isolation Systems Subjected to Horizontal and Vertical Components of Near-Fault Ground Motions
}

\author{
Fabio Mazza*, Alfonso Vulcano and Mirko Mazza
}

Dipartimento di Strutture, Università della Calabria, 87036 Rende (Cosenza), Italy

\begin{abstract}
Near-fault ground motions are characterized by long-duration horizontal pulses and high values of the peak vertical acceleration, which can become critical for a base-isolated structure. In order to check if current code provisions can be considered adequate for the design of base-isolated structures located in a near-fault area, base-isolated five-storey r.c. framed buildings with elastomeric bearings acting alone ("Base Isolation" system) or combined in parallel or in series with sliding bearings ("Base Isolation and in-Parallel Sliding", BIPS, or "Base Isolation and in-Series Sliding”, BISS, systems) are studied. The base-isolated structures are designed assuming the same values for the fundamental vibration period and equivalent viscous damping in the horizontal direction. Different values of the stiffness ratio, defined as the ratio between the vertical and horizontal stiffness of the elastomeric bearings, are considered; moreover, different values of the sliding ratio, defined as the global sliding force corresponding to an examined BIPS or BISS system divided by the maximum sliding force (in the case of a sliding bearing under each column), are also assumed. The nonlinear analysis of the test structures subjected to strong near-fault ground motions is performed using a step-by-step procedure based on a twoparameter implicit integration scheme and an initial-stress-like iterative procedure. At each step of the analysis, plastic conditions are checked at the potential critical sections of the girders (i.e. end sections of the sub-elements in which a girder is discretized) and columns (i.e. end sections), where a bilinear moment-curvature law is adopted. The response of an elastomeric bearing is simulated by a model with variable stiffness properties in the horizontal and vertical directions, depending on the axial force and lateral deformation, and linear viscous damping. Finally, a rigid-plastic (with friction variability) law is assumed to simulate the behaviour of a sliding bearing.
\end{abstract}

Keywords: Base-isolated buildings, Elastomeric and sliding bearings, Near-fault ground motions, Nonlinear dynamic analysis.

\section{INTRODUCTION}

Different techniques aimed at enhancing the seismic performance of a structure through base-isolation [1-7] or energy dissipation [8-12] systems have been proposed in literature. Specifically, base-isolation of a structure subjected to an earthquake allows a considerable reduction in the horizontal loads transmitted to the superstructure by using deformable devices (e.g. rubber-bearings) acting alone or in combination with frictional devices (e.g. flat steel-PTFE sliding bearings). Other isolation devices using curved surface sliders (e.g. friction pendulum) or rolling isolators (e.g. sphere devices) are also available in literature [1-3]. The following isolation strategies, or a suitable combination of them, can be used [13]: increase in the fundamental vibration period of the structure, to shift it into the range of low spectral accelerations; limitation of the maximum force transmitted to the superstructure, as a function of the friction coefficient. In the case of elastomeric bearings acting alone ("Base Isolation", BI, systems) or combined in series with sliding bearings ("Base Isolation and in-Series Sliding", BISS, systems), the structure behaves as isolated or fixed-base along

\footnotetext{
*Address correspondence to this author at the Dipartimento di Strutture, Università della Calabria, 87036 Rende (Cosenza), Italy;

Tel: +39 (0)984-496908; Fax: +39 (0)984-494045;

E-mail: fabio.mazza@unical.it
}

the vertical direction depending on the value, very low or very high, respectively, of the ratio $\alpha_{\mathrm{K} 0}\left(=\mathrm{K}_{\mathrm{V} 0} / \mathrm{K}_{\mathrm{H} 0}\right)$ between the vertical $\left(\mathrm{K}_{\mathrm{V} 0}\right)$ and horizontal $\left(\mathrm{K}_{\mathrm{H} 0}\right)$ nominal stiffnesses of the isolation system. Moreover, the Base Isolation with in Parallel Sliding (BIPS) systems are expected to behave as a fixed-base structure in the vertical direction, providing the grid of girders placed at the level of the isolation system with a high stiffness. In this case, the base-isolated structure behaves as a fixed-base structure also in the horizontal direction until the friction threshold of the sliding bearings is not exceeded.

Near-fault ground motions are characterized by longduration horizontal pulses and high values of the ratio $\alpha_{\mathrm{PGA}}\left(=\mathrm{PGA}_{V} / \mathrm{PGA}_{\mathrm{H}}\right)$ between the peak value of the vertical acceleration $\left(\mathrm{PGA}_{\mathrm{V}}\right)$ and the analogous value of the horizontal acceleration $\left(\mathrm{PGA}_{\mathrm{H}}\right)$, which can become critical for a base-isolated structure. More specifically, the horizontal deformability of a base-isolated structure may amplify the inelastic response of the superstructure and induce failure of the isolation system [14-16]. Moreover, high values of $\alpha_{\mathrm{PGA}}$ can notably modify the axial load in r.c. columns and the ductility demand along the span of the girders $[17,18]$, while elastomeric and sliding bearings can undergo tensile loads [19] and uplifts [20], respectively.

In the present work, different in-plan combinations and configurations of elastomeric and sliding bearings are compared referring to base-isolated five-storey r.c. framed build- 


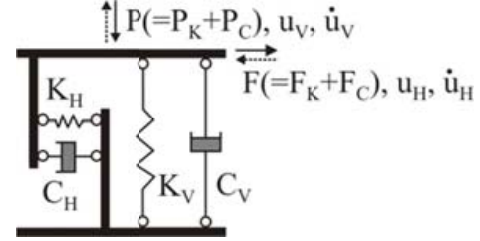

(a) Elastomeric bearing (e.g., HDLR bearing).

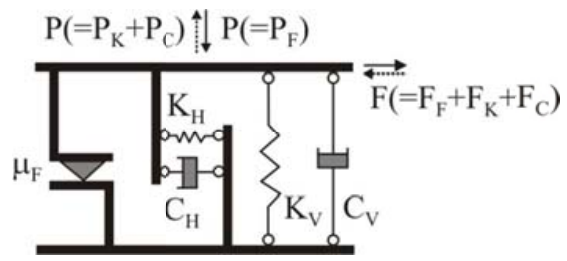

(c) In-parallel combination of elastomeric and sliding bearings (BIPS system: e.g., R-FBI).

Fig. (1). Modeling of base-isolation systems.

ings located in a near-fault area and designed according to the Italian Technical Regulations for Constructions (NTC08) [21], which includes many of the EC8 provisions [22]. The effectiveness of NTC08 rules is investigated considering the test structures subjected to horizontal and vertical near-fault ground motions.

\section{MODELING OF THE BASE-ISOLATED R.C. FRAMED STRUCTURES}

\subsection{Base-isolation Systems}

Base-isolation systems in most applications make use of elastomeric and frictional bearings (e.g. see [2, 23, 24]), aimed at carrying the vertical loads (exhibiting a rather high vertical stiffness) and allow rather large horizontal displacements (exhibiting a low stiffness and/or strength in the horizontal direction). The main rubber bearings currently used are [1-3]: "Neoprene Bearings" (NBs), without steel reinforcing plates; "Low Damping natural Rubber Bearings" (LDRBs), in which the rubber is vulcanized to two thick steel end-plates and many thin steel shims; "High-Damping natural Rubber Bearings" (HDRBs), where the damping is increased by adding oils or resins and other proprietary fills; "Lead plug natural Rubber Bearings" (LRBs), where a lead core is inserted in a laminated rubber bearing. The large horizontal base displacement consequent to a near-fault ground motion can be enabled by oversizing the elastomeric bearings (e.g., increasing the geometric dimensions of the rubber layers); it can be reduced increasing the roughness of the sliding surface of the frictional bearings.

An elastomeric bearing may act in parallel with a sliding bearing (e.g., the "Resilient-Friction Base Isolator", R-FBI) or in series with a sliding plate (e.g., the "Electricité de France" system, EDF) attached to its top or bottom surface. However, the Base Isolation with in-Parallel Sliding (BIPS) system can increase the contribution of the higher vibration modes of the superstructure, while the Base Isolation with in-Series Sliding (BISS) system is not favourable in reducing the residual displacement of the isolation system; as a consequence, this solution has not been frequently used because

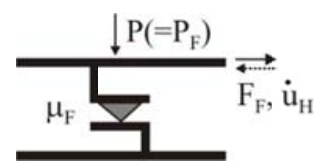

(b) Frictional bearing (e.g., steel-PTFE bearing).

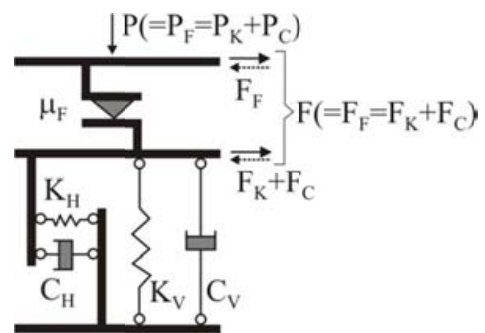

(d) In-series combination of elasitomeric bearing and sliding plates (BISS system: e.g., EDF).

re-centring during an earthquake and subsequent shocks is an important requirement of a base-isolation system.

The response of the above illustrated base-isolation systems can be simulated by adopting the models shown in Fig. (1). More specifically, Figs. (1a and 1b) refer, respectively, to elastomeric and frictional bearings, while Figs. (1c and 1d) represent, respectively, BIPS and BISS systems.

Elastomeric bearings (e.g. HDRBs) provide energy dissipation and re-centring capability. The experimental results of Ryan et al. [25] pointed out that the horizontal stiffness of a HDRB (starting from $\mathrm{K}_{\mathrm{H} 0}$ ) decreases with increasing vertical load $(\mathrm{P})$, while the corresponding vertical stiffness (starting from $\mathrm{K}_{\mathrm{V} 0}$ ) decreases with increasing lateral deformation $\left(\mathrm{u}_{\mathrm{H}}\right)$.

To account for the observed behaviour, the two-springtwo-dashpot model shown in Fig. (1a), constituted by a nonlinear spring acting in parallel with a linear viscous dashpot both in the horizontal and vertical directions, can be adopted [19]. The nonlinear force-displacement laws for the horizontal $\left(\mathrm{F}_{\mathrm{K}}-\mathrm{u}_{\mathrm{H}}\right)$ and vertical $\left(\mathrm{P}-\mathrm{u}_{\mathrm{V}}\right)$ springs are given as $([1,25])$

$$
\begin{aligned}
& F_{K}=K_{H} u_{H}=K_{H O}\left[1-\left(P / P_{c r}\right)^{2}\right] u_{H} \\
& P_{K}=K_{V}\left(u_{V}-\frac{a_{b}}{a_{K O}} \frac{16}{\pi^{2} \phi_{b} S_{2}} u_{H}^{2}\right)
\end{aligned}
$$

where the compressive or tensile critical load $\left(\mathrm{P}_{\mathrm{cr}}\right)$ and the vertical stiffness $\left(\mathrm{K}_{\mathrm{V}}\right)$ can be obtained according to experimental observations $([25,26])$ and, after some manipulation, can be specialized for a circular bearing of diameter $\phi_{b}$ as

$$
\begin{aligned}
& P_{c r}= \pm\left(\pi \phi_{b} / 4\right) K_{H O} \sqrt{a_{K O}} \\
& K_{V}=K_{V O} /\left[1+48\left(u_{H} / \pi \phi_{b}\right)^{2}\right]
\end{aligned}
$$

where $\alpha_{b}=h_{b} / t_{r}, h_{b}$ and $t_{r}$ are the total height of the bearing and the thickness of the rubber, respectively (e.g., $\alpha_{b}=1.2$ can be considered as a mean value); $\mathrm{S}_{2}=\phi_{\mathrm{b}} / \mathrm{t}_{\mathrm{r}}$, the secondary 


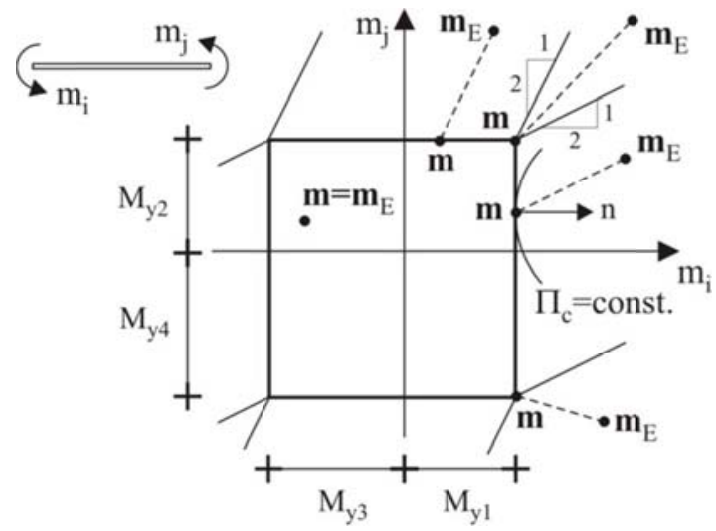

Fig. (2). Elastic-plastic solution of a r.c. frame member according to the Haar-Kàrmàn principle.

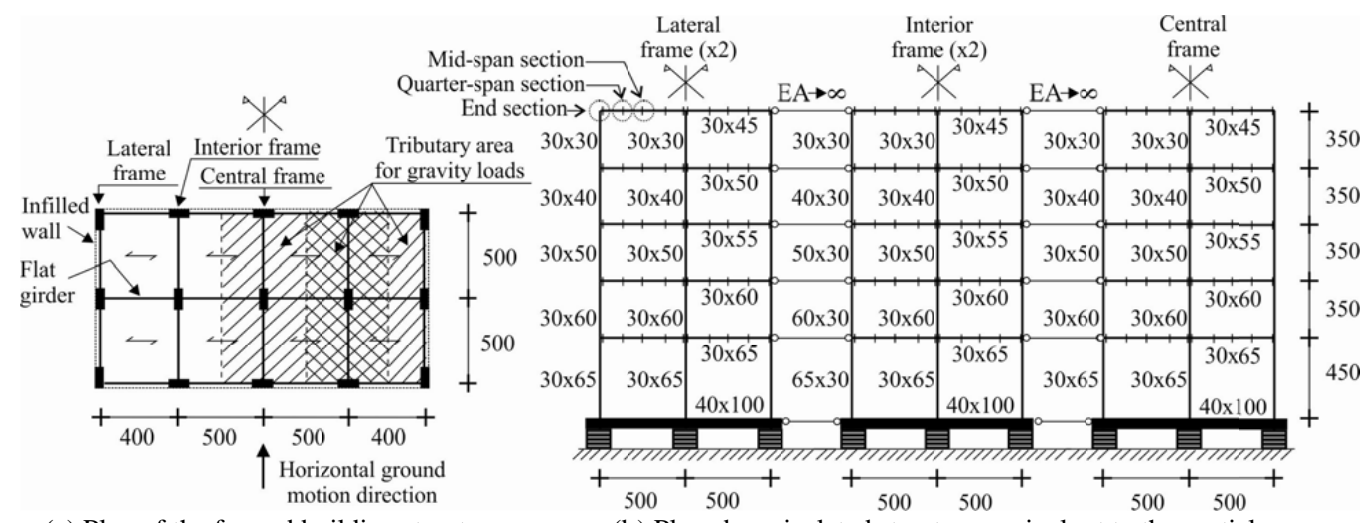

(a) Plan of the framed building structure.

(b) Plane base-isolated structure equivalent to the spatial one.

Fig. (3).Reference base-isolated r.c. framed structure (dimensions in $\mathrm{cm}$ ).

shape factor (e.g., $S_{2} \geq 4$ is a conservative assumption against buckling).

Moreover, the linear force-velocity laws for the horizontal $\left(\mathrm{F}_{\mathrm{C}}-\dot{\mathrm{u}}_{\mathrm{H}}\right)$ and vertical $\left(\mathrm{P}_{\mathrm{C}}-\dot{\mathrm{u}}_{\mathrm{v}}\right)$ dashpots in Fig. (1a) are expressed as

$F_{C}=C_{H} \dot{u}_{H} \cong\left(\zeta_{H} K_{H 0} T_{1 H} / \pi\right) \dot{u}_{H}$

$P_{C}=C_{V} \dot{u}_{V} \cong\left(\zeta_{V} K_{V 0} T_{1 V} / \pi\right) \dot{u}_{V}$

where $\zeta_{\mathrm{H}}\left(\xi_{\mathrm{V}}\right)$ and $\mathrm{T}_{1 \mathrm{H}}\left(\mathrm{T}_{1 \mathrm{~V}}\right)$ represent the equivalent viscous damping ratio and the fundamental vibration period in the horizontal (vertical) direction, respectively.

The response of a steel-PTFE sliding bearing (Fig. (1b)) basically depends on sliding velocity, contact pressure and temperature (e.g. see [27]). More specifically, the coefficient of sliding friction increases with increasing velocity up to a certain velocity value, beyond which it remains almost constant, while it drops with increasing pressure (with a rate of reduction that is dependent on sliding velocity) and temperature. The frictional force at the sliding interface can be expressed as

$F_{F}=\mu_{F} \cdot P \cdot Z$

$\mu_{F}=\mu_{\max }-\left(\mu_{\max }-\mu_{\min }\right) \cdot e^{-a \dot{u}_{H}}$

where $\mathrm{Z}$ is a dimensionless hysteretic quantity ( $\mathrm{Z}$ takes values of \pm 1 during sliding and less than unity during sticking) and $\mu_{\mathrm{F}}$ is the coefficient of friction at sliding velocity $\dot{\mathrm{u}}_{\mathrm{H}}$, which attains the value $\mu_{\max }$ or $\mu_{\min }$ respectively at high or very low velocity, while $\alpha$ is a constant for given values of pressure and temperature.

\subsection{R.C. Framed Structure}

The r.c. frame members are idealized by means of a twocomponent model, constituted by an elastic-plastic component and an elastic component, assuming a bilinear momentcurvature law. The effect of the axial load on the ultimate bending moment of the columns (M-N interaction) is also considered, assuming that both the axial and shear strains are fully elastic. At each step of the analysis, the elastic-plastic solution is evaluated in terms of the initial state and the incremental load on the basis of a holonomic law, as a solution of the Haar-Kàrmàn principle [15]. More specifically, by imposing plastic conditions on the bending moments $\left(\mathrm{m}_{\mathrm{i}}\right.$ and $m_{j}$ ) at the end sections ( $i$ and $j$ ) of each frame element, the elastic-plastic solution can be obtained considering, among the equilibrated internal forces $\mathbf{m}=\left(\mathrm{m}_{\mathrm{i}}, \mathrm{m}_{\mathrm{j}}\right)^{\mathrm{T}}$, the one which proves to be closest to the elastic solution $\mathbf{m}_{\mathrm{E}}=\left(\mathrm{m}_{\mathrm{Ei}}, \mathrm{m}_{\mathrm{Ej}}\right)^{\mathrm{T}}$ and satisfying the complementary energy minimum condition for the self-equilibrated internal forces $\left(\mathbf{m}-\mathbf{m}_{\mathrm{E}}\right)$. The above solution can be easily obtained by using the three-step algorithm illustrated in Fig. (2), where $\mathrm{M}_{\mathrm{y} 1}\left(\mathrm{M}_{\mathrm{y} 4}\right)$ and $\mathrm{M}_{\mathrm{y} 3}$ $\left(\mathrm{M}_{\mathrm{y} 2}\right)$ represent, respectively, the yield moments producing tension at the top and bottom of the end section $\mathrm{i}(\mathrm{j})$ :

$m_{i}^{\prime}=\max \left\{-M_{y 3}, \min \left\{M_{y 1}, m_{E i}\right\}\right\}$ 


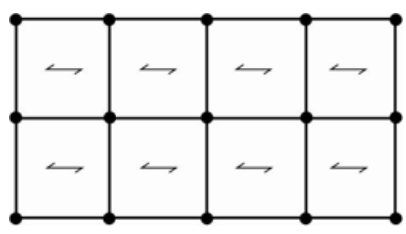

(a) BI.

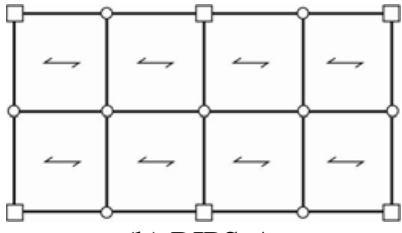

(b) BIPS-A.

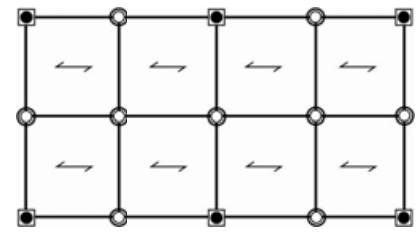

(e) BISS-A.
- HDLRB type 1

- HDLRB type 2

- HDLRB type 3

Steel-PTFE sliding bearing

HDLRB type $1+$ steel-PTFE sliding bearing

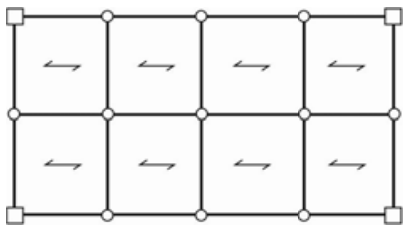

(c) BIPS-B.

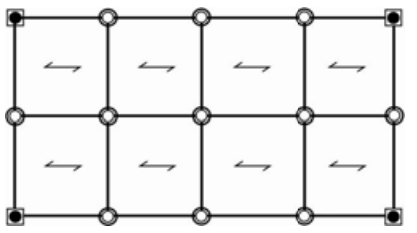

(f) BISS-B.

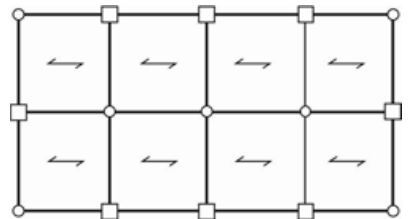

(d) BIPS-C.

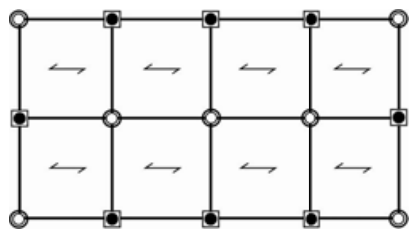

(g) BISS-C.

Fig. (4). In-plan layout of the base-isolation systems.

$m_{j}=\max \left\{-M_{y 4}, \min \left\{M_{y 2}, m_{E j}-\frac{1}{2}\left(m_{E i}-m_{i}^{\prime}\right)\right\}\right\}$

$m_{i}=\max \left\{-M_{y 3}, \min \left\{M_{y l}, m_{E i}-\frac{1}{2}\left(m_{E j}-m_{j}\right)\right\}\right\}$

\section{DESIGN OF THE BASE-ISOLATED R.C. FRAMED STRUCTURES}

A typical five-storey residential building, with a r.c. framed structure isolated at the base by different systems (Fig. (3)), is considered as a reference for the numerical investigation. Because of the structural symmetry and assuming the floor slabs are infinitely rigid in their own plane, the entire structure is idealized by an equivalent plane frame along the horizontal motion direction (Fig. (3b)), whose elements have stiffness and strength properties so that the two lateral frames, the two interior frames and the central one can be represented as a whole. The tributary mass resulting from the overall building and the gravity loads corresponding to the tributary area marked in Fig. (3a) are considered for each of them, assuming infilled walls placed along the perimeter of the building as non-structural elements regularly distributed in elevation. Length and crosssections of the frame members are also shown in Fig. (3).

Specifically, different in-plan combinations and configurations of elastomeric and sliding bearings are considered: elastomeric bearings (i.e. BI configuration in Fig. (4a): HDRBs type 1, which are simply assumed with the same dimensions); in-parallel combinations of elastomeric and sliding bearings (i.e. BIPS-A, BIPS-B and BIPS-C configurations in Figs. 4b, 4c and 4d, respectively, using HDRBs type 2); in-series combinations of elastomeric and sliding bearings (i.e. BISS-A, BISS-B and BISS-C configurations in Figs. $\mathbf{4 e}, \mathbf{4 f}$ and $\mathbf{4 g}$, respectively, using HDRBs type 3 and sliding bearings placed in the same position adopted for the BIPS systems but in-series with HDRBs type 1). Each ar- rangement of elastomeric and sliding bearings corresponds to a value of the nominal sliding ratio $\alpha_{\mathrm{S} 0}\left(=\mathrm{F}_{\mathrm{S} 0} / \mathrm{F}_{\mathrm{S} 0 \text {,max }}\right)$, defined, under gravity loads, as the global sliding force $\left(\mathrm{F}_{\mathrm{S} 0}\right)$ corresponding to an examined BIPS (Figs.4b, $\mathbf{4 c}$ and $\mathbf{4 d}$ ) or BISS (Figs. $\mathbf{4 e}, \mathbf{4 f}$ and $\mathbf{4 g}$ ) system divided by the maximum sliding force $\left(\mathrm{F}_{\mathrm{S} 0, \max }\right)$, this latter evaluated supposing that elastomeric and sliding bearings (or plates) are placed under each column. Three values of the nominal stiffness ratio of the HDRBs (i.e. $\alpha_{\mathrm{K} 0}=200,800,2000$ ) are considered for the BI, BIPS-A and BISS-A structures, while $\alpha_{K 0}=800$ is assumed for the BIPS-B, BIPS-C, BISS-B and BISS-C ones. The base-isolated structures are designed assuming the same values of the fundamental vibration period in the horizontal direction (i.e. $\mathrm{T}_{1 \mathrm{H}}=2.5 \mathrm{~s}$ ) and equivalent viscous damping ratios in the horizontal (i.e. $\xi_{\mathrm{H}}=10 \%$ ) and vertical (i.e. $\xi_{\mathrm{v}}=5 \%$ ) directions. Moreover, the equivalent viscous damping of the sliding bearings ( $\left.\xi_{\mathrm{HS}}\right)$ is calculated referring to the (horizontal) spectral displacement, considering the gravity loads and a sliding friction coefficient $\mu_{\mathrm{F}}=0.03$. For each of the thirteen cases considered in the analysis, the following data are reported in Table 1: nominal values of the stiffness $\left(\alpha_{\mathrm{K} 0}\right)$ and sliding $\left(\alpha_{\mathrm{S} 0}\right)$ ratios; equivalent viscous damping of the elastomeric $\left(\xi_{\mathrm{HI}}\right)$ and sliding $\left(\xi_{\mathrm{HS}}\right)$ bearings, in the horizontal direction; diameter of the HDRBs $\left(\phi_{\mathrm{b}}\right)$ and corresponding primary $\left(S_{1}\right)$ and secondary $\left(S_{2}\right)$ shape factors; compression modulus of the rubber-steel composite bearing $\left(\mathrm{E}_{\mathrm{c}}\right)$.

The proportioning of the test structures is done assuming, besides the gravity loads, the horizontal and vertical seismic loads corresponding to the same value of the behaviour factor (i.e. $\mathrm{q}_{\mathrm{H}}=\mathrm{q}_{\mathrm{V}}=1.5$ ). Moreover, the following design assumptions are made: moderately soft soil (class $\mathrm{D}$, subsoil parameters: $\mathrm{S}_{\mathrm{SH}}=1.45$ in the horizontal direction and $\mathrm{S}_{\mathrm{SV}}=1$ in the vertical one); flat terrain (class T1, topographic parameter: $\mathrm{S}_{\mathrm{T}}=1$ ); high-risk seismic region (peak ground acceleration in the horizontal, $\mathrm{PGA}_{\mathrm{H}}$, and vertical, $\mathrm{PGA}_{\mathrm{V}}$, directions equal to $0.404 \mathrm{~g}$ and $0.278 \mathrm{~g}$, respectively). The gravity loads 
Table 1. Geometric and mechanical properties of the base-isolation systems.

\begin{tabular}{|c|c|c|c|c|c|c|c|c|c|c|c|}
\hline Test structure & $\alpha_{\mathrm{K} 0}$ & $\alpha_{\mathrm{S} 0}$ & $\xi_{\mathrm{HI}}(\%)$ & $\xi_{\mathrm{HS}}(\%)$ & $\phi_{\mathrm{b}}(\mathbf{c m})$ & $\mathbf{S}_{1}$ & $\mathbf{S}_{2}$ & $\mathbf{E}_{\mathrm{c}}(\mathbf{M P a})$ & $\gamma_{\mathrm{s}}$ & $\gamma_{\text {tot }}$ & $\mathbf{P} / \mathbf{P}_{\mathrm{cr}}$ \\
\hline \multirow{3}{*}{ BI } & 200 & - & 10 & - & 107 & 5.61 & 2.20 & 63 & 0.48 & 2.15 & 0.50 \\
\hline & 800 & - & 10 & - & 68 & 12.28 & 3.30 & 262 & 1.14 & 3.64 & 0.50 \\
\hline & 2000 & - & 10 & - & 52 & 24.20 & 4.22 & 676 & 1.95 & 5.00 & 0.47 \\
\hline \multirow{3}{*}{ BIPS-A } & 200 & 0.59 & 3.12 & 6.88 & 72 & 5.72 & 4.86 & 66 & 1.62 & 5.00 & 0.46 \\
\hline & 800 & 0.42 & 5.84 & 4.16 & 63 & 12.54 & 5.25 & 271 & 1.98 & 5.00 & 0.38 \\
\hline & 2000 & 0.35 & 5.97 & 4.03 & 63 & 24.76 & 5.29 & 693 & 2.00 & 3.68 & 0.21 \\
\hline BIPS-B & 800 & 0.22 & 7.69 & 2.31 & 63 & 12.43 & 4.88 & 267 & 1.77 & 5.00 & 0.44 \\
\hline BIPS-C & 800 & 0.62 & 2.64 & 7.36 & 66 & 12.68 & 5.54 & 276 & 2.00 & 4.08 & 0.24 \\
\hline \multirow{3}{*}{ BISS-A } & 200 & 0.30 & 6.37 & 3.63 & 90 & 5.63 & 3.80 & 64 & 0.99 & 3.87 & 0.50 \\
\hline & 800 & 0.30 & 7.24 & 2.76 & 65 & 12.43 & 4.85 & 267 & 1.78 & 5.00 & 0.44 \\
\hline & 2000 & 0.30 & 6.51 & 3.49 & 63 & 24.72 & 5.27 & 692 & 2.00 & 3.80 & 0.22 \\
\hline BISS-B & 800 & 0.17 & 8.14 & 1.86 & 63 & 12.42 & 4.82 & 266 & 1.76 & 5.00 & 0.44 \\
\hline BISS-C & 800 & 0.43 & 4.70 & 5.30 & 66 & 12.54 & 5.42 & 271 & 1.95 & 5.00 & 0.37 \\
\hline
\end{tabular}

used in the design are represented by dead- and live-loads, respectively equal to: $4.3 \mathrm{kN} / \mathrm{m}^{2}$ and $1 \mathrm{kN} / \mathrm{m}^{2}$, for the top floor; $5 \mathrm{kN} / \mathrm{m}^{2}$ and $2 \mathrm{kN} / \mathrm{m}^{2}$, for the other floors. The contribution of the masonry-infills is taken into account considering a weight of $2.7 \mathrm{kN} / \mathrm{m}^{2}$. The following masses are considered at each floor: lumped masses at the exterior and interior joints, in order to take into account the contribution of the transverse girders and, in the case of the exterior joints, also that of the masonry infills; uniformly distributed mass along the girders and columns, accounting for the gravity load of the structural member and, in the case of a girder, also for that of the floor slab and masonry infills (only for girders of lateral frames). A cylindrical compressive strength of 25 $\mathrm{N} / \mathrm{mm}^{2}$ for concrete and a yield strength of $450 \mathrm{~N} / \mathrm{mm}^{2}$ for steel are assumed.

The design of the superstructure was carried out satisfying minimum conditions for the longitudinal bars of the girders and columns, according to the provisions for low ductility class imposed by NTC08: at least two $14 \mathrm{~mm}$ bars are provided both at the top and bottom throughout the length of all the frame members; for the girders, a tension reinforcement ratio not less than $0.31 \%$ (for the assumed yield strength) is provided and, at their end sections, a compression reinforcement not less than half of the tension reinforcement is placed; a minimum steel geometric ratio of $1 \%$ is assumed for the symmetrically-reinforced section of each column.

The design of the HDRBs was carried out according to the prescriptions imposed by NTC08, assuming a shear modulus of the elastomer $\mathrm{G}=0.35 \mathrm{MPa}$. In particular, the Ultimate Limit State (ULS) verifications regarding the maximum shear strains have been satisfied: i.e. $\gamma_{\text {tot }}=\gamma_{s}+\gamma_{c}+\gamma_{\alpha} \leq 5$ and $\gamma_{s} \leq 2$, where $\gamma_{\text {tot }}$ represents the total design shear strain, while $\gamma_{s}, \gamma_{c}$ and $\gamma_{\alpha}$ represent the shear strains of the elastomer due, respectively, to seismic displacement, axial compression and angular rotation. Moreover, the maximum compression axial load (P) has not exceeded the critical load ( $\mathrm{P}_{\mathrm{cr}}$; see (eq.3)) divided by a safety coefficient equal to 2.0. Finally, the minimum tensile stress $\left(\sigma_{t}\right)$ resulting from the seismic analysis has been assumed as $2 \mathrm{G}(=0.7 \mathrm{MPa})$ for all the elastomeric bearings. In Table 1 the results of the ULS verifications for the HDRBs are also reported. As can be observed, the design of the HDRBs is controlled by the condition imposed on the maximum shear strains (i.e. $\gamma_{\text {tot }}$ and $\gamma_{s}$ ), with some exceptions for BI (i.e. $\alpha_{\mathrm{K} 0}=200$ and 800) and BISS-A (i.e. $\alpha_{\mathrm{K} 0}=200$ ) structures where the buckling control proved to be the more restrictive $\left(\mathrm{P} / \mathrm{P}_{\mathrm{cr}}=0.50\right)$. No tensile axial loads were found.

\section{NUMERICAL RESULTS}

In order to study the nonlinear dynamic response of the BI, BIPS and BISS structures subjected to near-fault ground motions, a numerical investigation is carried out by using a step-by-step procedure $[14,18]$. At each step of the analysis, plastic conditions are checked at the potential critical sections of the girders and columns using a bilinear model with a hardening ratio of $5 \%$. In order to take into account the plastic deformations along the girders, each of them is discretized into four sub-elements of equal length; in this way, the potential critical sections correspond to end, quarter-span and mid-span sections in Fig. (3b). In the Rayleigh hypothesis, the damping matrix of the superstructure is assumed as a linear combination of the mass and stiffness matrices, assuming a viscous damping ratio of $2 \%$ in both the horizontal $\left(\xi_{\mathrm{H}}\right)$ and vertical $\left(\xi_{\mathrm{V}}\right)$ directions with reference to the two vibration periods $\left(\mathrm{T}_{1 \mathrm{H}}\right.$ and $\left.\mathrm{T}_{1 \mathrm{~V}}\right)$ corresponding to higherparticipation modes with prevailing contributions in the horizontal and vertical direction, respectively. The local damage undergone by the frame members is evaluated considering the ductility demand calculated in terms of curvature, with reference to the two loading directions, assuming as yielding curvature for the columns the one corresponding to the axial load due to the gravity loads. The response of the isolation systems is simulated using the models described in Section 2. The ultimate values of the total shear strain $\left(\gamma_{\text {tot,u }}\right)$ and the corresponding shear strain due to seismic displacement $\left(\gamma_{\mathrm{s}, \mathrm{u}}\right)$ of a HDRB are assumed equal to $7.5(=1.5 \times 5)$ and $3(=1.5 \times 2)$, respectively (i.e. 1.5 times the design values); moreover, the compressive and tensile axial loads are limited, respectively, to the critical buckling load $\left(\mathrm{P}_{\mathrm{cr}}\right)$, evaluated according to eq. (3), and the tensile value $\left(\mathrm{P}_{\mathrm{tu}}\right)$, obtained multiplying the reduced effective area by a limit stress tension $\sigma_{\mathrm{tu}}=0.7 \mathrm{MPa}$. The sliding friction coefficient $\mu_{\mathrm{F}}$ is 
Table 2. Main data of the selected near-fault ground motions.

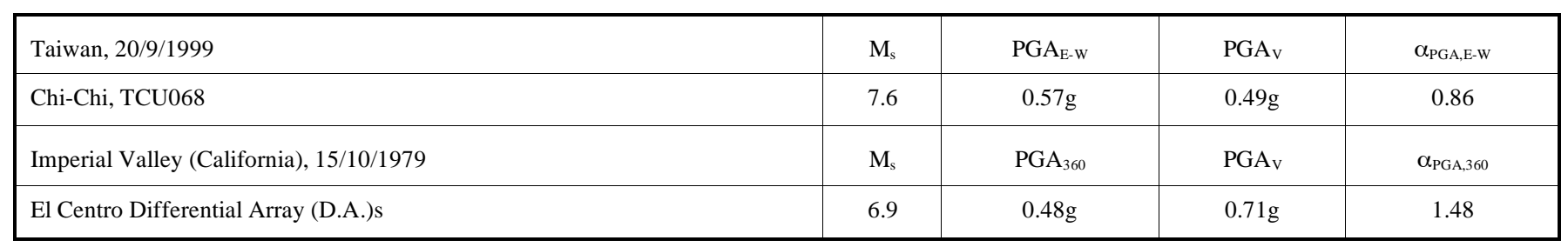

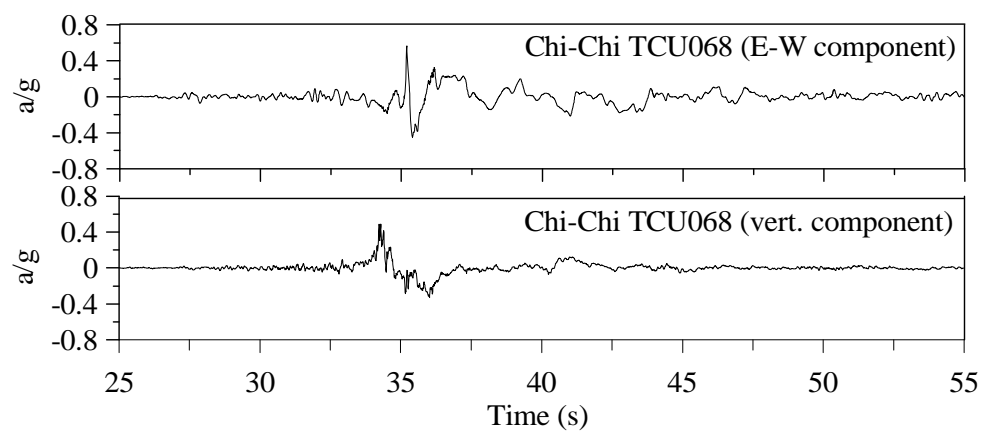

(a) Taiwan, Chi-Chi station, 20/9/1999.

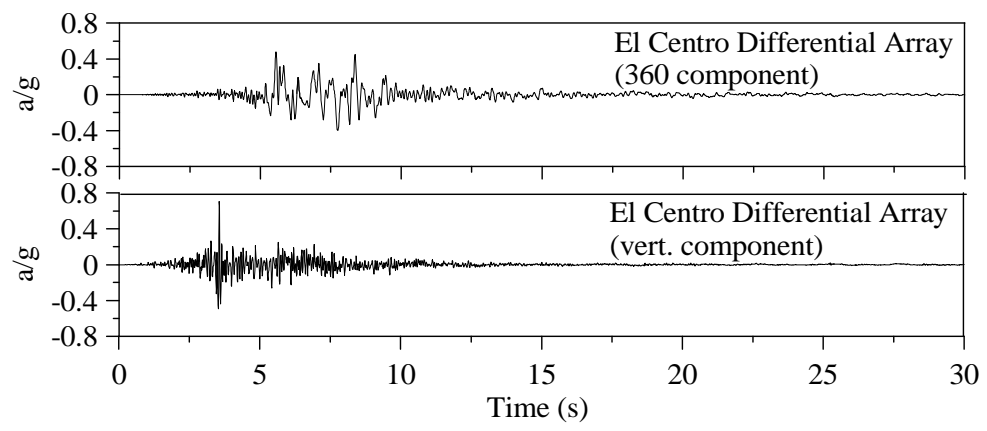

(b) California (Imperial Valley), El Centro Differential Array station, 15/10/1979.

Fig. (5). Recorded acceleration components considered in the analysis.

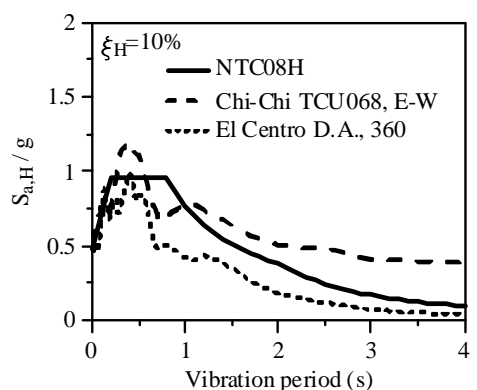

(a) Horizontal direction

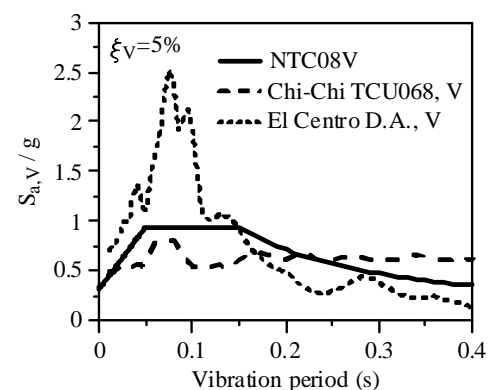

(b) Vertical direction.

Fig. (6). Pseudo-acceleration response spectra.

evaluated for mean values of contact pressure and temperature, e.g. assuming $\mu_{\min }=3 \%, \mu_{\max }=15 \%$ and $\alpha=0.02 \mathrm{~s} / \mathrm{mm}$ in the eq. (8) (see [27]). According to the design hypotheses adopted for the test structures (i.e. subsoil class D and highrisk seismic region), accelerograms recorded on soft soil, with a $\mathrm{PGA}_{\mathrm{H}}$ value approximately comparable with the one prescribed by NTC08 $\left(\mathrm{PGA}_{\mathrm{H}}=0.404 \mathrm{~g}\right)$, are considered. More specifically, near-fault ground motions recorded at Taiwan in 1999 (Chi-Chi TCU068 station: E-W and vertical components) and Imperial Valley in 1979 (El Centro D.A. station: horizontal, 360, and vertical components), available in the Pacific Earthquake Engineering Research center database
(PEER, 2008) [28], have been considered. In Table 2 the main data of the selected ground motions are reported: recording station, magnitude $\left(\mathrm{M}_{\mathrm{s}}\right)$, peak ground acceleration for the selected horizontal component and the vertical component, and acceleration ratio $\alpha_{\mathrm{PGA}}$. It is interesting to note that large horizontal pulses have been observed in the ChiChi earthquake (Fig. 5a); on the other hand, the El Centro D.A. earthquake (Fig. 5b) is characterized by a high value of the acceleration ratio $\alpha_{\mathrm{PGA}, \mathrm{EW}}\left(=\mathrm{PGA}_{\mathrm{V}} / \mathrm{PGA}_{360}=1.48\right)$.

The corresponding elastic response spectra of normalized pseudo-acceleration $\left(\mathrm{S}_{\mathrm{a}} / \mathrm{g}\right)$ are plotted in Fig. (6), assuming 


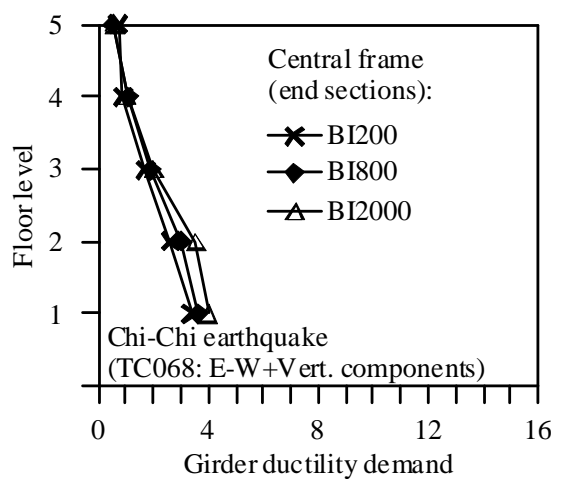

(a)

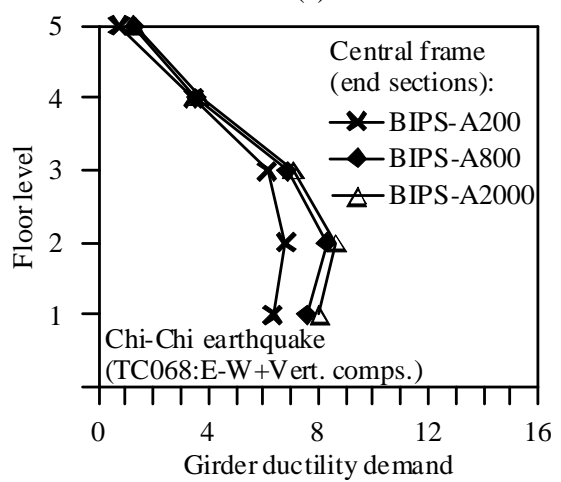

(c)

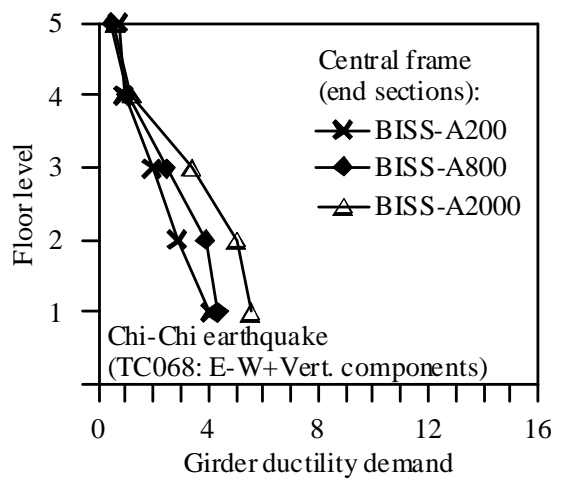

(e)

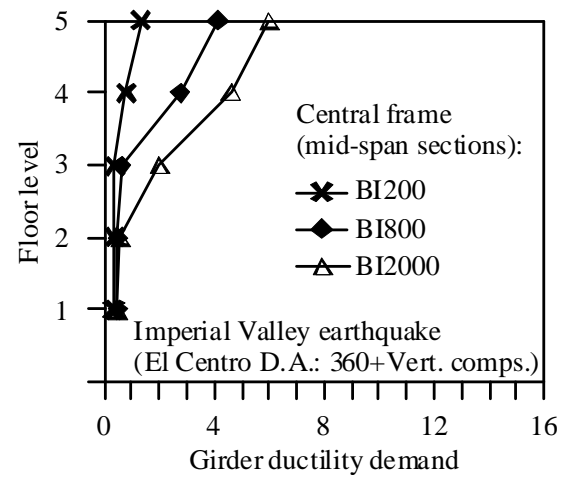

(b)

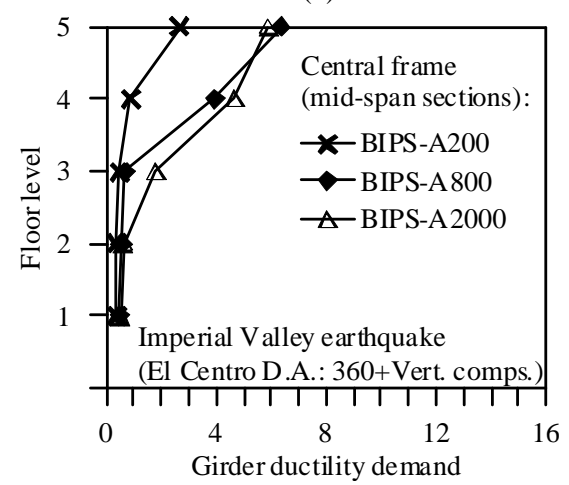

(d)

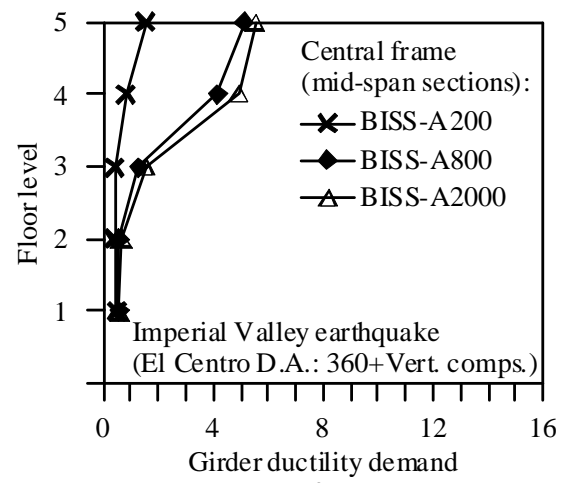

(f)

Fig. (7). Influence of the nominal stiffness ratio $\alpha_{\mathrm{K} 0}\left(=\mathrm{K}_{\mathrm{V} 0} / \mathrm{K}_{\mathrm{H} 0}\right)$ on the ductility demand of BI, BIPS and BISS structures.

an equivalent viscous damping ratio in the horizontal direction, $\xi_{\mathrm{H}}$, equal to $10 \%$, and an analogous ratio in the vertical direction, $\xi_{\mathrm{V}}$, equal to $5 \%$. The response spectra are compared with the corresponding target NTC08 response spectrum for a high-risk seismic region and a soft soil (class D): i.e. $\mathrm{PGA}_{\mathrm{H}}=0.404 \mathrm{~g}$ and $\mathrm{PGA}_{\mathrm{V}}=0.278 \mathrm{~g}$. It is interesting to note that, in the range of rather long vibration periods (i.e. $\mathrm{T}_{\mathrm{H}} \geq 2.5$ $\mathrm{s}$ ), corresponding to the base-isolated structures which will be examined successively, the spectral values for the E-W component of Chi-Chi motion are greater than those corresponding to NTC08 and the El Centro earthquake (Fig. 6a). Moreover, in the vertical direction higher spectral values are obtained for El Centro D.A. motion (Fig. 6b), at least for rather low values of the vibration periods (i.e. $T_{V}<0.16 \mathrm{~s}$ ), which are more interesting for several test structures (see Table 1).

Firstly, in order to emphasize the effects due to the horizontal and vertical components of near-fault ground motions on the inelastic response of the superstructure, the numerical investigation is carried out with reference to the BI (Figs. 7a,b), BIPS-A (Figs. 7c,d) and BISS-A (Figs. 7e,f) baseisolation systems. To this end, mean ductility demand at all the floor levels is reported for the end-sections (Figs. 7a,c,e: Chi-Chi ground motion) and mid-span sections (Figs. 7b,d,f: El Centro D.A. ground motion) of the girders. For the sake of brevity, only the results for the central frame, having a tributary area for gravity loads greater than those corresponding to the lateral and interior frames (see Fig. 3a), are reported for three values of the nominal stiffness ratio $\alpha_{\mathrm{K} 0}=\mathrm{K}_{\mathrm{V} 0} / \mathrm{K}_{\mathrm{H} 0}$ (i.e. 200, 800 and 2000). It should be noted that the nonlinear dynamic analyses were first stopped at the time when a limit state was reached: i.e., the total shear strain of the HDRBs or the ductility demand at the end-sections of the girders, under Chi-Chi motions; the ductility demand at the mid-span sections of the girders, under El Centro D.A. motions. Afterwards, in order to make the results comparable, the analyses were repeated assuming the minimum value among those already evaluated as the final instant of simulation, for each ground motion and base-isolation system. 


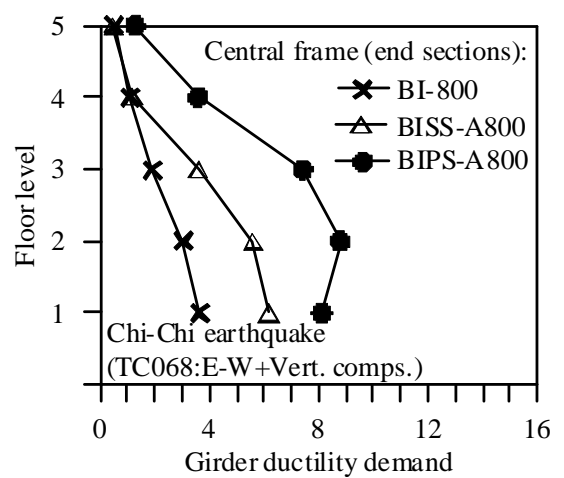

(a)

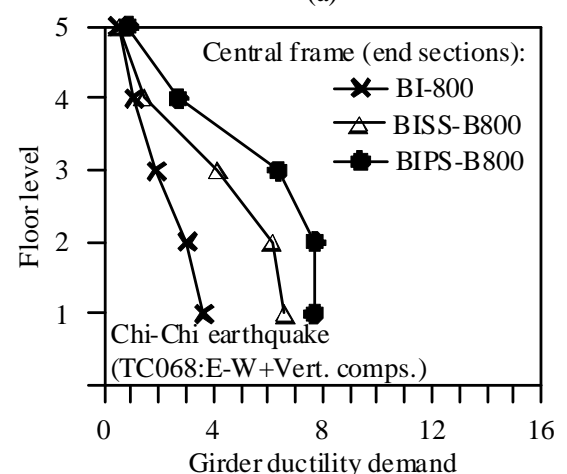

(c)

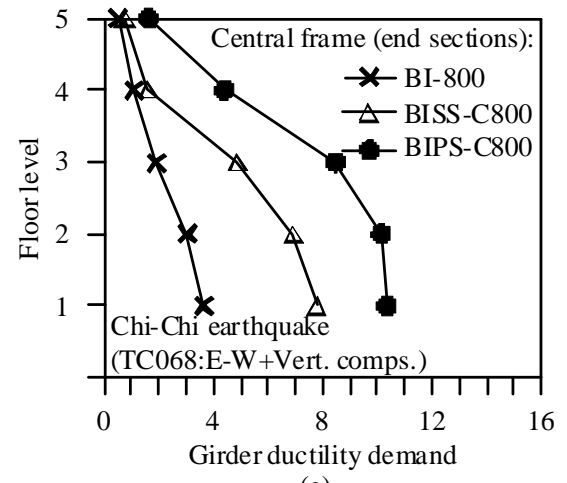

(e)

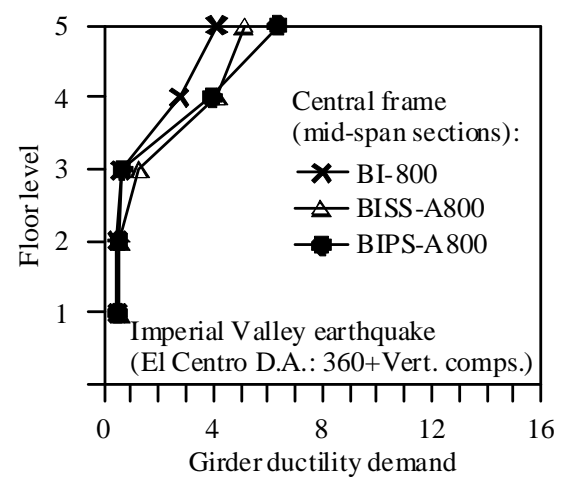

(b)

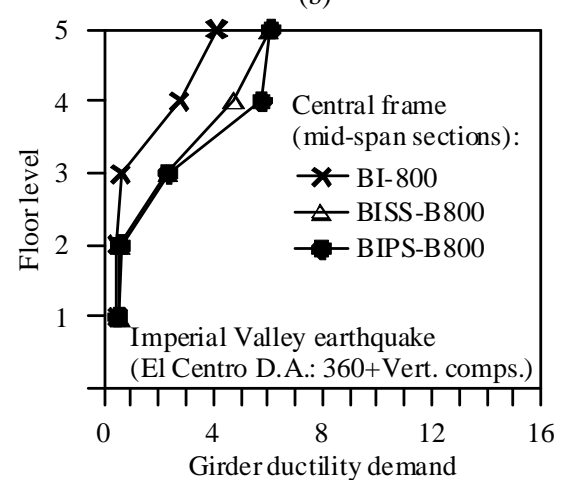

(d)

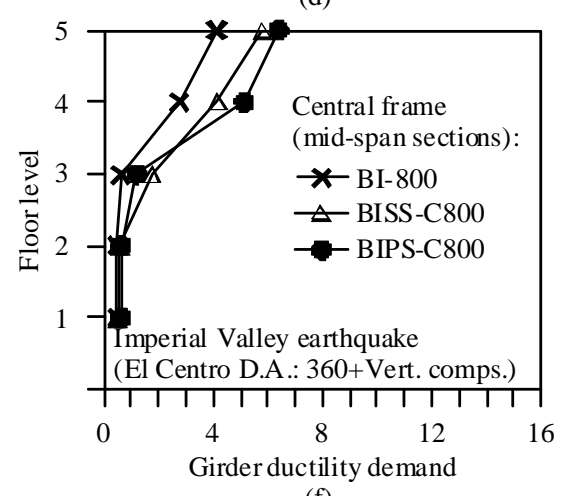

(f)

Fig. (8). Influence of the nominal sliding ratio $\alpha_{\mathrm{S} 0}\left(=\mathrm{F}_{\mathrm{S} 0} / \mathrm{F}_{\mathrm{S} 0 \text {,max }}\right)$ on the ductility demand of BI, BIPS and BISS structures.

The results obtained for Chi-Chi ground motion (Figs. 7a,c,e), characterized by high values of the (horizontal) pseudo-acceleration in the range of rather long vibration periods (i.e. $\mathrm{T}_{1 \mathrm{H}} \geq 2.5 \mathrm{~s}$ ), have highlighted that unexpected ductility demand are made on the lower floors. This result is more evident for BIPS-A structures (Fig. 7c), whose behaviour in the horizontal direction is that of a fixed-base structure until the friction threshold imposed by the sliding bearings is not exceeded. Moreover, it is interesting to note that, in all the cases, the limited influence of the $\alpha_{K 0}$ value on the ductility demand is observed. As observed in a previous work by the authors [18], the E-W component of Chi-Chi earthquake also leads to ductility demand at the end sections of columns, especially in the lower storeys.

On the other hand, under the El Centro D.A. ground motion (Figs. 7b,d,f), characterized by high values of the vertical pseudo-acceleration, at least for rather low values of the vibration periods (i.e. $\mathrm{T}_{1 \mathrm{HV}}<0.16 \mathrm{~s}$ ), the mid-span sections of the girders undergo increasing plastic deformations for an increasing $\alpha_{\mathrm{K} 0}$ value, especially on the upper floors. This behaviour can be explained observing that for rather low values of $\alpha_{\mathrm{K} 0}$ (e.g. $\left.\alpha_{\mathrm{K} 0}=200\right)$ the superstructure above the BI and BISS-A systems can be considered as isolated along the vertical direction, exhibiting a basically elastic behaviour, while for rather high values of $\alpha_{\mathrm{K} 0}$ (e.g. $\left.\alpha_{\mathrm{K} 0}=2000\right)$ the same superstructure can be assumed as a fixed-base structure with reference to the same direction. Moreover, a behaviour similar to that of a fixed-base structure is expected in the vertical direction for the BIPS-A systems.

Analogous curves to those shown above for the girders are reported in Fig. (8) to compare the response of the BIPS and BISS base-isolation systems assuming, for the same value of $\alpha_{\mathrm{K} 0}$ (i.e. $\alpha_{\mathrm{K} 0}=800$ ), three different in-plan configurations of elastomeric and sliding bearings (see Fig. 4). Moreover, curves corresponding to the BI structure are also reported for a comparison. As regards the ductility demand of the end sections, the results show that for Chi-Chi ground motion (Figs. 8a,c,e) both the BIPS and BISS systems have 


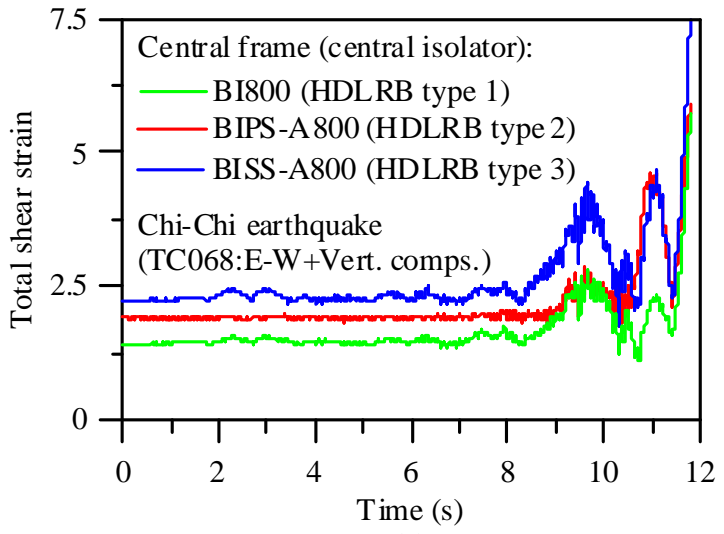

(a)

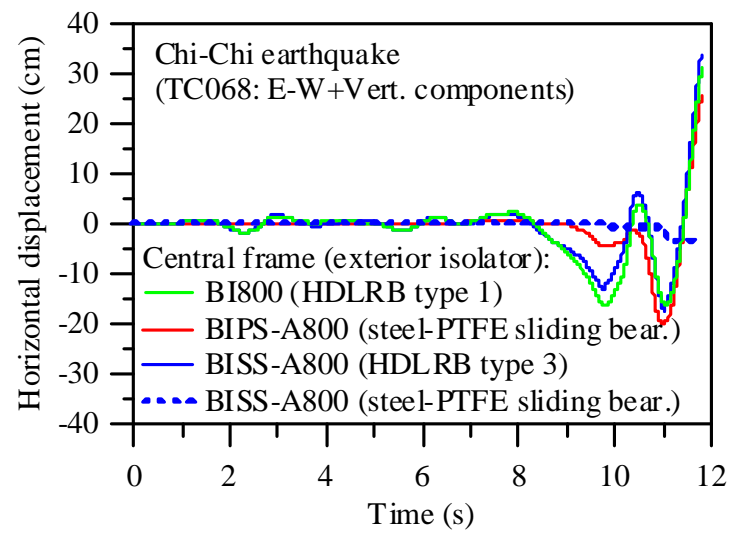

(b)

Fig. (9). Time histories for base-isolation systems of BI, BIPS and BISS structures.

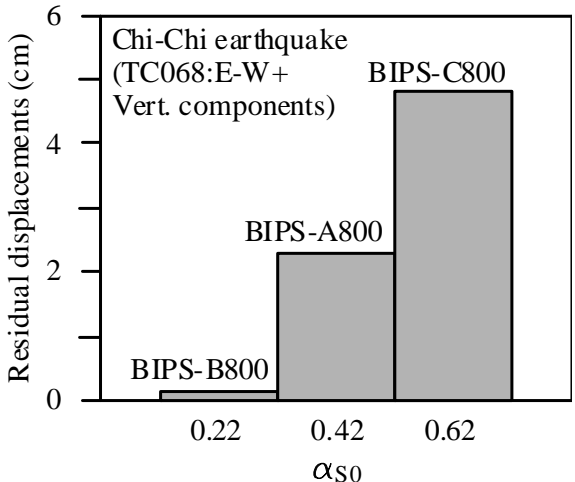

(a)

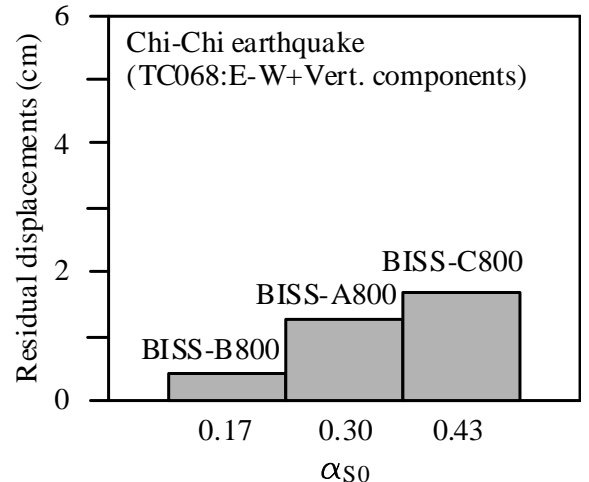

(b)

Fig. (10). Residual displacement of the sliding bearings for BIPS and BISS structures.

not improved the performance of the superstructure which becomes even worse than that observed for the BI structure.

This is evident for higher values of the nominal sliding ratio $\alpha_{\mathrm{S} 0}\left(=\mathrm{F}_{\mathrm{S} 0} / \mathrm{F}_{\mathrm{S} 0 \text {, max }}\right)$ when using BIPS systems (see Table 1), because the structural behaviour in the horizontal direction tends to becomes ever-closer to that of a fixed-base structure. The BISS systems prove to be generally more effective than the BIPS ones for limiting the structural damage of the framed structure, producing elongation in the effective fundamental vibration period, thus limiting the maximum horizontal acceleration transmitted to the superstructure. On the other hand, the ductility demand of the mid-span sections are plotted in Figs. $(\mathbf{8 b}, \mathbf{d}, \mathbf{f})$ for BIPS and BISS systems subjected to Imperial Valley ground motion. As can be observed, the in-plan configuration of elastomeric and sliding bearings proves to be of little importance, producing only moderate differences in the ductility demand on the upper floors where it is still higher than that obtained for the BI structure. Moreover, it is worth noting that the influence of $\alpha_{S 0}$ is less evident for the El Centro D.A. motion than for the Chi-Chi one. The ductility demand for the columns, not shown for the sake of brevity, increases on the top storey for increasing values of $\alpha_{\mathrm{K} 0}$.

The response of the base-isolated structures is strongly affected by the behaviour of the elastomeric and sliding bearings. In particular, the effectiveness of the BIPS and BISS systems in controlling the shear strain and horizontal dis- placement of the isolator has been investigated assuming the same value of $\alpha_{\mathrm{K} 0}$ (i.e. 800). More specifically, time histories of the total shear strain $\left(\gamma_{\text {tot }}\right)$ for the central isolator of the BI800, BIPS-A800 and BISS-A800 systems subjected to Chi-Chi ground motion are plotted in Fig. (9a). For all the cases the failure occurs before the end of motion, because the limit value $\gamma_{\text {tot,u }}$ is exceeded. In Fig. (9b), analogous curves represent time histories of the horizontal displacement of elastomeric and/or sliding bearings for the exterior isolator of the central frame. As can be observed, the BIPS-A800 system proved to be the most favourable to control the elastomeric-isolator displacement, at least in the first $10.5 \mathrm{~s}$, because the behaviour is similar to that of a fixed-base structure until the friction threshold of the sliding bearings is not reached. Residual displacement of the sliding bearings is plotted in Fig. (10) for different in-plan configurations of the BIPS (Fig. 10a) and BISS (Fig. 10b) systems subjected to Chi-Chi ground motion. It should be noted that both systems can need re-centring after an earthquake in case the restoring force of the HDRBs does not exceed the friction threshold of the sliding bearings. More specifically, both BIPS and BISS systems undergo increasing residual displacements for increasing values of $\alpha_{\mathrm{S} 0}$.

Moreover, there may be some additional difficulties in the re-centring of a BISS system after an earthquake in case of out-of-phase movements between the isolators and the sliding bearings placed on them. 


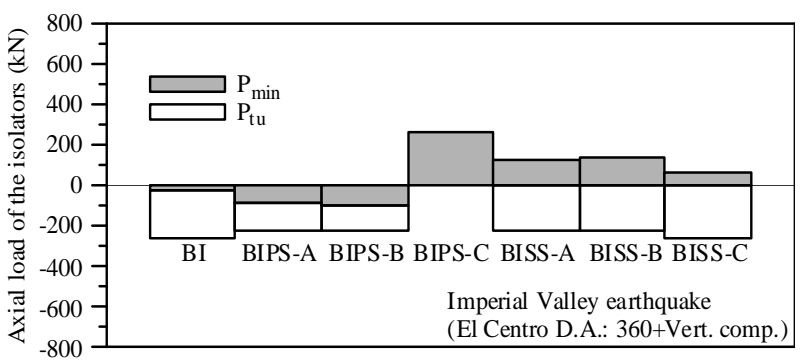

Fig. (11). Axial load of the central isolator of a lateral frame (BI, BIPS and BISS structures; $\alpha_{\mathrm{K} 0}=800$ ).

Finally, histograms representing the minimum axial load $\left(\mathrm{P}_{\min }\right)$ attained by the central isolator of the lateral frame and the corresponding ultimate tensile axial load $\left(\mathrm{P}_{\mathrm{tu}}\right)$ are plotted in Fig. (11) for BI, BIPS and BISS systems subjected to El Centro D.A. ground motion. More specifically, different values of $\alpha_{S 0}$ are assumed for both the BIPS and BISS systems, considering the same value of $\alpha_{\mathrm{K} 0}$ (i.e. $\alpha_{\mathrm{K} 0}=800$ ). As can be observed, tensile axial loads have been attained by the above isolator of the BI, BIPS-A and BIPS-B structures but the $P_{t u}$ value was never reached. Moreover, the maximum (compressive) axial load in the isolators, not shown for brevity, proves to be much less than the corresponding critical buckling load $\left(\mathrm{P}_{\mathrm{cr}}\right)$.

\section{CONCLUSIONS}

The nonlinear seismic response of five-storey r.c. baseisolated framed structures, with different in-plan combinations and configurations of elastomeric and sliding bearings, has been studied under near-fault ground motions. Different values of the nominal stiffness ratio $\alpha_{\mathrm{K} 0}$, for the HDRBs, and nominal sliding ratio $\alpha_{S 0}$, for the steel-PTFE sliding plates, are considered. Under a pulse-type horizontal component of a near-fault motion (e.g. Chi-Chi earthquake), the adoption of BI, BIPS and BISS systems can induce unexpected ductility demand at the end sections of both girders and columns, especially in the lower storeys. This result is more evident for increasing values of $\alpha_{S 0}$, especially when using a BIPS system, whose behaviour in the horizontal direction tends to become ever-closer to that of a fixed-base structure. A high value of the peak vertical acceleration of the ground motion (e.g. Imperial Valley earthquake) produces ductility demand which is rather evident at the mid-span sections of the girders, especially in the upper floors when assuming a rather high value of $\alpha_{\mathrm{K} 0}$, for which the superstructure behaves like a fixed-base structure in the vertical direction. The BIPS system is more effective than the BISS one for controlling the horizontal displacement of the isolation system; both systems can need re-centring after an earthquake in case the restoring force of the HDRBs does not exceed the friction threshold of the sliding plates corresponding to the $\alpha_{S_{0}}$ value. Moreover, there may be some additional difficulties in the re-centring of a BISS system after an earthquake in case of out-of-phase movements between the isolators and the sliding bearings placed on them. Finally, the isolators can undergo tensile loads, especially when the vertical component of the ground motion has a relatively high peak value.

The above considerations indicate that the effects of the horizontal and vertical components of near-fault ground motions should be taken into account through suitable addi- tional code provisions. In particular, some caution is needed in designing the superstructure and the base-isolation system especially when assuming rather high values of $\alpha_{\mathrm{K} 0}$ and $\alpha_{\mathrm{S} 0}$, respectively. However, to draw any firm conclusions, further research is needed to extend the study to other structures and recorded near-fault ground motions to represent many structural and ground shaking situations.

\section{CONFLICT OF INTEREST}

The authors confirm that this article content has no conflicts of interest.

\section{ACKNOWLEDGEMENTS}

The present work was financed by RELUIS (Italian network of university laboratories of earthquake engineering), according to "Convenzione D.P.C. - RELUIS 2010-2013, task 2.3.2",

\section{REFERENCES}

[1] F. Naeim, and J.M. Kelly, Design of seismic isolated structures: from theory to practice, Wiley \& Sons Ltd: NY, 1999.

[2] F. Mazza, and A. Vulcano, "Sistemi di controllo passivo delle vibrazioni", Progettazione sismo-resistente di edifici in cemento armato (in italian), Città Studi Edizioni, Novara (Italy), vol. 11, pp. 525-575, 2011.

[3] D. Foti, and M. Mongelli, "Isolatori sismici", (in italian), Dario Flaccovio Editore, Palermo, 2011, pp. 1-280.

[4] D. Ordoñez, D. Foti, and L. Bozzo, "Comparative study of the inelastic response of base isolated buildings", Earthquake Engineering and Structural Dynamics, vol. 32, no. 1, pp. 151-164, 2003.

[5] F. A. Martelli, and M. Forni, "Seismic isolation and other antiseismic systems: recent applications in Italy and worldwide", Seismic Isolation And Protection Systems (SIAPS), Mathematical Sciences Publishers (MSP): Berkeley (California), vol. 1, no. 1, pp. 75-123, 2010.

[6] R. Greco, G. Marano, and D. Foti, "Strong motion duration effects on base isolated systems", Physica A - Statistical Mechanics and its Applications, vol. 274, no. 1-2, Amsterdam, North Holland, 1999.

[7] L.D. Tirca, D. Foti, and M. Diaferio, "Response of middle-rise steel frames with and without passive dampers to near-field ground motions", Engineering Structures, vol. 25, no. 2, pp. 169-179, 2003

[8] J. Molina, S. Sorace, G. Terenzi, G. Magonette, and B. Viaccoz, "Seismic tests on reinforced concrete and steel frames retrofitted with dissipative braces", Earthquake Engineering and Structural Dynamics, vol. 33, no. 12, pp. 1373-1394, 2004.

[9] L. Shuang, and L.-L.Xie, "Progress and trend on near-field problems in civil engineering", ActaSeismologicaSinica, vol. 20, no. 1, pp. 105-114, 2007.

[10] F.C. Ponzo, A. Di Cesare, D. Nigro, A. Vulcano, F. Mazza, M. Dolce, and C. Moroni, "JET-PACS project: dynamic experimental tests and numerical results obtained for a steel frame equipped with hysteretic damped chevron braces", Journal of Earthquake Engineering, vol. 16, pp. 662-685, 2012.

[11] F. Mazza, and A. Vulcano, "Control of the along-wind response of steel framed buildings by using viscoelastic or friction dampers", Wind \& Structures, vol. 10, no. 3, pp. 233-247, 2007.

[12] F. Mazza, and A. Vulcano, "Control of the earthquake and wind dynamic response of steel-framed buildings by using additional braces and/or viscoelastic dampers", Earthquake Engineering \& Structural Dynamics, vol. 40, pp. 155-174, 2011.

[13] F. Braga, M. Faggella, R. Gigliotti, and M. Laterza, "Nonlinear dynamic response of HDRB and hybrid HDRB-friction sliders base isolation systems", Bulletin of Earthquake Engineering, vol. 3, pp. 333-353, 2005.

[14] A. Vulcano, and F. Mazza, "Nonlinear dynamic analysis of baseisolated framed structures subjected to horizontal and vertical ground motions", International Symposium on Recent Advances in Mechanics, Dynamical Systems and Probability Theory, MDP, Palermo (Italy), vol. 1, pp. 629-640, 2007. 
[15] F. Mazza, and A. Vulcano, "Nonlinear response of rc framed buildings with isolation and supplemental damping at the base subjected to near-fault earthquakes", Journal of Earthquake Engineering, vol. 13, no. 5, pp. 690-715, 2009.

[16] F. Mazza, and A. Vulcano, "Effects of horizontal and vertical nearfault ground motions on the nonlinear dynamic response of rc buildings with different base-isolation systems", $14^{\text {th }}$ World Conference on Earthquake Engineering, Beijing (China), paper no. 1130, 2008.

[17] F. Mazza, and A. Vulcano, "Nonlinear dynamic response of R.C. framed structures subjected to near-fault ground motions", Bulletin of Eathquake Engineering, vol. 8, pp. 1331-1350, 2010.

[18] F. Mazza, and A. Vulcano, "Effects of near-fault ground motions on the nonlinear dynamic response of base-isolated R.C. framed buildings", Earthquake Engineering and Structural Dynamics, vol. 41, pp. 211-232, 2012.

[19] A. Kasalanati, and M.C. Constantinou, "Testing and modeling of prestressed isolators", Journal of Structural Engineering, vol. 131, pp. 857-866, 2005.

[20] K.L. Ryan, and A.K. Chopra, "Estimating seismic demands for isolation bearings with building overturning effects", Journal of Structural Engineering, vol. 132, pp. 1118-1128, 2006.

[21] Technical Regulations for the Constructions. Italian Ministry of the Infrastructures, January 14, 2008 (in italian).
[22] Eurocode 8. Design of Structures for Earthquake Resistance - Part 1: General Rules, Seismic Actions and Rules for Buildings. C.E.N., European Committee for Standardisation, December 2003.

[23] F. Mazza, and A. Vulcano, "Comparison among base isolation techniques for r.c. buildings subjected to near-fault earthquakes", $14^{\text {th }}$ European Conference on Earthquake Engineering, Skopije, Republic of Macedonia, paper no. 337, 2010.

[24] F. Mazza, M. Mazza, and A. Vulcano, "Effectiveness of NTC08 rules for the design of base-isolated framed structures located on a near-fault area" (in italian), XIV Convegno ANIDIS, L'Ingegneria Sismica in Italia, Bari (Italy), paper no. 1057, 2011.

[25] K.L. Ryan, J.K. Kelly, and A.K. Chopra, "Experimental observation of axial load effects in isolation bearings", Proceedings of the $13^{\text {th }}$ World Conference on Earthquake Engineering, Vancouver (Canada), paper no. 1707, 2004.

[26] J.M. Kelly, "Tension buckling in multilayer elastomeric bearings", Journal of Engineering Mechanics, vol. 129, pp. 1363-1368, 2003.

[27] M. Dolce, D. Cardone, and F. Croatto, "Frictional behaviour of steel-PTFE interfaces for seismic isolation", Bulletin of Earthquake Engineering, vol. 3, pp. 75-99, 2005.

[28] Pacific Earthquake Engineering Research center, "Next Generation Attenuation (NGA) database", 2008. Available at: http://peer.berkeley.edu/peer_ground_motion_database.

(C) Mazza et al.; Licensee Bentham Open.

This is an open access article licensed under the terms of the Creative Commons Attribution Non-Commercial License (http://creativecommons.org/licenses/by-nc/3.0/) which permits unrestricted, non-commercial use, distribution and reproduction in any medium, provided the work is properly cited. 